\title{
Koya city gas distribution network
}

\author{
J. A. Ali \\ Petroleum Engineering Department, Faculty of Engineering, \\ Koya University, Koya, Kurdistan, Iraq
}

\begin{abstract}
The world demand for energy is increasing every year due to a rising population. Koya city, as a part of this world, has expanded in area and population. Therefore, providing fuel for the city via tankers and vehicles might be difficult and cause road accidents. This study investigates the designing of a gas distribution network for the city of Koya. Extending the pipeline service could supply gas to Koya's residents in a modern way and reduce road traffic. The aim of the study is to deliver clean energy for transport, residential, industrial and commercial needs. The project's plan, development, operation, and application are a complex task that needs real support from Kurdistan Government, particularly the local authority and Koya University.
\end{abstract}

\section{Introduction}

Liquefied Petroleum Gas (LPG) is a mixture of hydrocarbons, which are in gaseous state at ambient temperature and pressure but these are liquefied under pressure for easy storage, handling and transportation in pressurized vessels. It is obtained through crude oil refining or from natural gas through fractionation. Butane and Propane are the main constituent hydrocarbons in LPG. Others present in traces or small fractions are Iso-butane, butylene, n-butane, propylene etc. [1]. Although the gas cylinder in Koya city and Kurdistan can be obtained from local shops, it is difficult to deal with. The old style of the gas cylinders, Figure 1, which is used nowadays in Koya and Kurdistan householder's kitchens, should be replaced. These cylinders have too many disadvantages; the main one is the wrong way of keeping them at homes which might cause fire. In addition, it is difficult to be obtained and moved to the houses due to the heavy weight of these cylinders. The current study investigates the process of building pipelines network to distribute gas for Koya city residents. Oil and gas transmission 


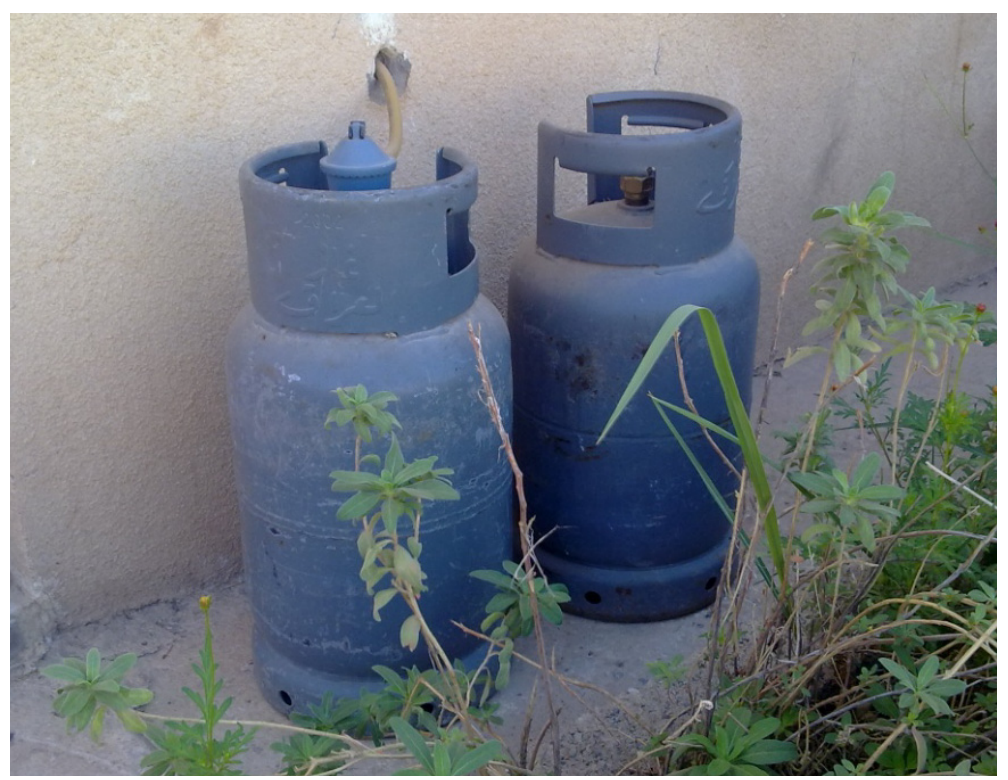

Figure 1: $\quad$ Gas cylinders.

Table 1: $\quad$ Comparison of modes of energy transportation [2, 4].

\begin{tabular}{|c|c|c|c|}
\hline Transport Mode & $\begin{array}{c}\text { Factor on } \\
\text { Death }\end{array}$ & $\begin{array}{c}\text { Factor on } \\
\text { Fire/Explosion }\end{array}$ & $\begin{array}{c}\text { Factor on } \\
\text { Injury }\end{array}$ \\
\hline Road Truck & 87.3 & 34.7 & 2.3 \\
\hline Rail & 2.7 & 8.6 & 0.1 \\
\hline Barge & 0.2 & 4.0 & 3.1 \\
\hline Tanker Ship & 4.0 & 1.2 & 1.0 \\
\hline Pipeline & 1.0 & 1.0 & \\
\hline
\end{tabular}

pipelines are a safe form of energy transportation compared to rail, road, and sea: Table 1 compares the safety of pipelines with these other transportation modes.

For example, road trucks cause 87.3 times more deaths than pipelines, and are 34.7 times more likely to cause a fire or explosion. Pipelines also have a low impact on the environment, both in terms of their presence and possible pollution [2]. The implementation of this project needs complicated routes (network) to reach the gas to every single house in the city, the extended pipes must be buried under ground. Whilst the normal recommendation in the UK is to have a 
minimum of $1.2 \mathrm{~m}$ cover (measured from the top of the pipe barrel to the finished road surface) under roads and $0.9 \mathrm{~m}$ elsewhere, it is sometimes necessary to lay pipes at less cover and the charts have been prepared with a minimum cover of $0.6 \mathrm{~m}$ in roads and fields, etc. However, special precautions should be taken to minimise the risk of mechanical damage during future excavations and reinstatement of other services, agricultural machinery, etc. [3].

\section{Discussion}

The project consists of the following:

- $\quad$ City gate station for storing gas, mother station will be stored at the city gate to supply gas to the smaller stations if exist.

- Basic grid from city gate station which normally operates at 19 bars for steel pipes.

- City would be divided into various wards to supply gas at regulates pressure (19- 4 bars).

- Distribution network of pipes from wards to consumption centres with maximum 4 bars. The network pipe diameter use between $2 \frac{1}{2}{ }^{\prime \prime}$ to 4 " depending on the gas demand and city population.

- Service lines from distribution network to meet the requirement of the households 4 bars via 1 " pipe.

- Risers provided in the building to supply to residential consumers where pressure is reduced up to 20 milibar [5].

- Internal fittings and metering are needed.

Figure 2 shows the network for connecting seven neighbourhoods (the nodes A, B ...) and the branches represent the pipelines, the shortest distance should be taken. The optimization method will be used to find out the right paths and distances.

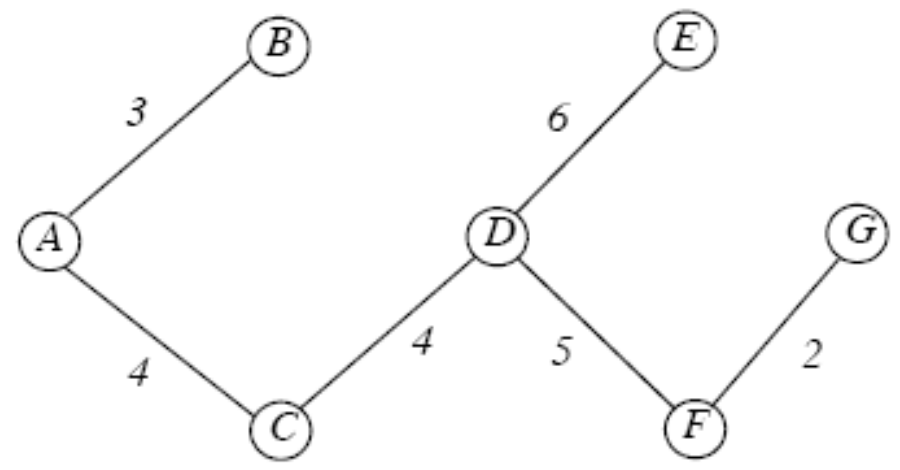

Figure 2: $\quad$ Optimization method for network with all connections. 


\section{Pipeline design requirements}

The successful implementation of pipeline network is subject to the following steps:

1. Surveys for market and future demand.

2. Required pressure.

3. Routes map.

4. Pipe diameter and length.

5. Pipe wall thickness.

6. Pipe specification/grade.

7. Materials selection.

8. Estimation of the total cost.

9. Detailed designed drawings.

\section{Direct impact on the city}

When the project of city gas distribution network come to success and applied to the city of Koya, great changes in the society and among housekeepers will be observed. This kind of project makes the life easier for people, easily obtain the gas via a pipe at home in a way similar to water. The city residents are not anymore lifting these heavy cylinders and paying for transportation. In addition, the city will get rid of these cylinders from the streets and local shops. Like any other developed countries across the world, people can get the gas whenever they want from their homes. So the all idea is to modernize the city of Koya and develop it in all directions by using the resent technology for urban development.

\section{Suggestions}

The project of city gas distribution is not new ideas, but it can be said that it will be new application in city of Koya particularly and Kurdistan generally. However, this project is similar to water city network which is exist for many years in Koya. In this study the following are suggested to make the project success:

1. Allocating budget: this might be provided by the local city council or funded by one of the oil industries in the region.

2. International regulator: based on the world regulation and classifications the project should be applied, in addition the international standards must be followed in design procedures.

3. Local city authority: the local authority in the city should assign and support the project, without their support the project cannot be done.

4. Gas suppliers: the oil and gas companies that do supply the local markets with gas should agree on that providing the project with the amount of gas that is needed for Koya. This will be by storing the gas in special tanks is made for that purpose.

5. Tank farm: few tanks are needed to build for storing gas then discharge it to the consumers. 


\section{References}

[1] Anon. “Air Duct Cleaning, LPG Gas Cylinder Tips” Internet: http://www.indiahometips.com/lpg-cylinder-tips.html, June 2013 [Oct. 07, 2013].

[2] P. Hopkins. "High design factor pipelines: integrity issues" The Journal of Pipeline Integrity, pp. 69 - 97, 2005.

[3] CPM Group “CPM Concrete Drainage System- Pipeline Design” Internet: http://www.cpm-group.com/downloads/Concrete-Pipe-InstallationGuide.pdf, [Oct. 08, 2013].

[4] Allegro Group: Association of Oil Pipe Lines “Oil pipeline safety: a research update” Internet: www.aopl.org , April 2000 [Oct. 08, 2013].

[5] Anon. "City gas distribution project in Chennai". Internet: http://www.docstoc.com/docs/126909969/City_Gas_Distribution_Project_In _Chennai, 2008 [Oct. 07, 2013]. 